\title{
A Study on Anxiety based on symptoms of ADHD, Creativity and Nicotine Consumption in Smokers
}

\author{
Sowmya Warrier ${ }^{1}$ \\ ${ }^{1}$ Post Graduate Student, Department of Psychology, Maniben Nanavati Women's College, Mumbai \\ E-mail-sowmyawarrier10@gmail.com
}

\begin{abstract}
This research aims at studying the predictive power of symptoms of Attention Deficit Hyperactivity Disorder, Creativity and Nicotine Consumption in relation to Trait anxiety in individuals who have been smoking for twelve months or more with an increase in the number of cigarettes over time. The State and Trait Anxiety (STAS) scale was used for the same. Symptoms of ADHD were measured by the Adults ADHD Self Report Scale. Divergent Thinking Test was used to measure Creativity of the individuals. Data was collected using the method of convenience sampling via the internet. The study comprised of eighty three participants ranging from nineteen to thirty five years of age. The results were analysed using a Multiple Linear Regression model after checking for the linearity of the variables using a Matrix Scatter Plot. Pearson's correlation was computed to determine the relationship between the variables. A positive and significant relationship was found between trait Anxiety and ADHD. A Linear Regression Model applied to study the variance between the two variables indicated that $13.9 \%$ of the variance in trait Anxiety can be explained by the presence of symptoms of ADHD. Results indicated that $A D H D$ is a significant predictor of Trait Anxiety. The study provides future implication to therapists working with clients with ADHD and Anxiety.
\end{abstract}

Key words: anxiety, trait anxiety, nicotine, smokers, $A D H D$, creativity.

\section{INTRODUCTION}

Hamilton distinguished between anxiety as a reaction to danger, as a pathological mood and a neurotic state or syndrome. There are several theories of anxiety that can be used to define and understand this construct. Sigmund Freud proposed two theories of anxiety in which he presented anxiety as an everyday phenomenon. He classified anxiety into three sub types; realistic or objective anxiety, neurotic anxiety and moral anxiety [1]. Several trait theorists like Eysenck and Cattell proposed concepts of neuroticism and personality factors after the process of factor analysis. These constructs form the basis of Spielberger's theory of State and Trait Anxiety (1960) [2]. He distinguished between anxieties as a reaction versus an underlying tendency to respond to threats. Trait refers to enduring and general dispositions to react to situations in a consistent manner; it involves the tendency to 
experience anxious symptoms in nonthreatening situations, it implies vulnerability to stress. State Anxiety is a discreet response to a particular situation.

A common consequence of anxiety is smoking behaviour. When an individual is faced with threat, danger or simply a difficult situation at work, resorting to lighting up a cigarette is very common. This is seen very often in high stress jobs and amongst those working in the creative fields. It has been researched that nicotine reaches the brain in about 10 seconds, having a relaxing and stimulating effect on the individual. When the individual is unable to smoke a cigarette it may give rise to feelings of withdrawal which in itself is very similar to the symptoms of anxiety. Despite these consequences, smoking as a result of anxiety is very common.

\section{Nicotine Consumption}

Smoking behaviour is prevalent in adolescents as well as adults world over. Reasons for initiation may vary from person to person however; the general pattern of progression of dependence remains more or less common to all individuals. As per the Diagnostic and Statistical Manual of Mental Disorders (DSM-IV-TR) published bythe American Psychiatric Association (2000) [3] the criteria for nicotine dependence includes a maladaptive pattern of nicotine use leading to clinically significant impairment or distress as manifested by three or more of the following criteria within a twelve month period such as tolerance, withdrawal, change in social and occupational activities.

The DSM-5 categorizes a variety of substance use disorders separately with criteria that provide a gradation of severity within each diagnostic category. Tobacco smoke also contains monoamine oxidase inhibitors (MAOI) that break down neurotransmitters like dopamine, serotonin and norepinephrine resulting in increased addiction to nicotine [4].

The DSM 5 classifies ADHD on the basis of severity i.e. mild, moderate and severe. A major complaint of adults with ADHD is that they are unable to organize and prioritize; they lose focus on tasks easily and are impatient. Low frustration tolerance, impulsivity, mood swings and trouble coping with stress are also prevalent symptoms. Inattention can be caused by both anxiety as well as ADHD and therefore it is of utmost importance to track the source of this inattention to either one or both of these entities. ADHD and anxiety have a high level of comorbidity; the disorders that often occur with ADHD are social phobia, generalized anxiety disorder, PTSD and panic disorder.

Creativity is the ability to produce work that is both novel (original, unexpected) and appropriate (useful, adaptive to test constraints) [5]. Creativity can be understood in several ways. One such understanding of creativity comes from convergent and divergent thinking. Divergent thinking refers to undertaking the search for solutions that may involve substantial departures from the commonly taken track. It involves using approaches that may be uncommon or unusual [5].

A study conducted in 2010 [6] proposed that anxiety modulates the function of attention. Double dissociation was seen in the results of this study. Trait anxiety was related to deficiencies in the executive control network, but state anxiety was associated with an over-functioning of the alerting and orienting responses. Another study aimed at identifying the relationship between different types of attention patterns and anxiety (state and trait). It aimed at studying how anxiety predicts the performance of students with ADHD. Results indicated that the groups differed significantly on attention and anxiety. Trait anxiety further predicted the individuals concentration 
abilities. A study [8] aimed at studying the dysregulation of attentional control in association with trait anxiety. It was found that TA is linked to impoverished attention control as a result of lowered prefrontal activity. Researchers have conducted a study to investigate the relationship of state and trait anxiety to performance on figural and verbal creative tasks [9]. In a study [10] aimed at studying the effect of anxiety on divergent thinking, it was found that divergent thinking did not significantly increase trait anxiety scores as the sample employed were comfortable with divergent problems.

\section{METHODOLOGY}

The predictor variables in this study are Nicotine content, Creativity and Symptoms of ADHD. The criterion variable in this study is Trait Anxiety.

Nicotine content : It is defined as the average amount of nicotine based on the number and brand of cigarettes smoked by an individual per day. The value will be calculated manually depending on the particulars of the brand chosen by the individual.

Trait Anxiety : It is defined as the stable individual differences in thetendency to respond with an increase in state anxiety when anticipating a threat situation. It is consistent across a broad range of situations and is temporarily stable. This variable will be measured using the State Trait Anxiety Inventory (STAI) (Speilberger, 1983) [2].

Creativity : It is defined as the ability to generate numerous and diverseideas and is influenced by situational and motivational factors. This variable will be measured using the Divergent Thinking Test by Marc Runco (2011).

Symptoms of ADHD : It can be defined as the presence of inattention,hyperactivity and impulsivity in visible proportions such that they may cause hindrance to the day to day functioning of the adult. A screening tool is used for the measurement of this variable i.e. Adult ADHD Self- Report Scale v-1.1 Symptom Checklist (2012).

This research uses a correlational design. It is a quantitative study that includes 3 predictor variables and 1 criterion variable. Symptoms of ADHD, creativity and nicotine content are the predictor variables and Trait Anxiety is the criterion variable. The total sample size of this study was 83 individuals consisting of twenty nine females and fifty four males ranging between 19-35 years of age. The method of convenience sampling was used to collect the data for this study. This study used an online method of data collection. The three scales as well as the specifics demographic details were uploaded as a Google doc. The document was accessible to both computer/ laptop users as well as mobile phone users. The process from start to end could be completed within an average of 20 minutes. The demographic details included information about the individuals smoking behaviours in terms of duration and extent. It also takes into account the individual's occupation, age, brand preference etc. The inclusion criteria for participants in this study was the duration of their smoking behaviour (participants who had been smoking for twelve months or more were included). It was also based on the number of cigarettes smoked (increase in the number of cigarettes smoked resulted in inclusion).

Scores on the State and Trait Anxiety Inventory (STAI) [2] were calculated manually as per the scoring instructions provided. Reversed scored items were accounted for and the raw score was computed. T scores for the same were obtained with reference to the individual's gender and age. T scores for State and Trait Anxiety were reported separately. Scores on both ranged from a minimum of 20 to a maximum of 80 . Nicotine content smoked by the individuals was calculated manually by 
taking into account the brand of the cigarette and the number of cigarettes smoked by the individual. The average nicotine content smoked by the individual was used for further analysis. The results were obtained in milligrams.

Screening for ADHD symptoms was done using the ADHD Self Report Scale v1.0 symptom Checklist (2012) [11]. The scale is divided into two parts (A and $B$ ). for the purpose of screening only part $A$ was used in this study. Responses were obtained in the form of a Likert scale. If the respondent marked 4 or more of the shaded options, he/she was categorised as having ADHD symptoms.

Creativity was measured using Divergent Thinking Test [12]. The respondents were given three figures one at a time and were asked to list down whatever they saw in these figures. The responses were scored on two out of three domains i.e. Originality and Fluency. Fluency refers to the total number of responses given per item per individual. Originality refers to the extent to which the responses given by the individual are novel or uncommon. Responses were coded as common or uncommon based on five percent of the total sample. When $5 \%$ of the sample responded to an item in a certain way that was common, the response was marked as a common response. The remaining responses are the uncommon responses. The number uncommon responses across all three figures per participant were calculated as the Originality score. The individuals score on creativity was the total of Fluency and Originality scores.

\section{Statistical Analysis}

The data was analysed using IBM SPSS version 17.0 for windows 7. A multiple linear regression model was chosen for the analysis of the data as the research aims at studying the predictive value of three variables one single outcome variable. A multiple regression model allows checking for multicollinearity between the predictor variables as well as doe linearity in the outcome variable.

\section{RESULTS}

The study consisted of twenty nine females and fifty four males ranging from nineteen years of age to thirty five years of age.

\begin{tabular}{cccc}
\multicolumn{5}{c}{ Table 1 } & \multicolumn{4}{c}{ Descriptive summary of the variables } \\
Variable & Mean & Standard Deviation & $\mathrm{N}$ \\
\hline TA & 55.487 & 6.54801 & 78 \\
ADHD & 2.12 & 1.554 & 78 \\
Creativity & 14.5641 & 8.67837 & 78 \\
Nicotine & 2.5821 & 1.99571 & 78 \\
\hline
\end{tabular}

The first test to checking if a Multiple Linear Regression (MLR) can be done is to check for linearity. The results on the matrix scatter Plot shows that basic linearity can be assumed. 


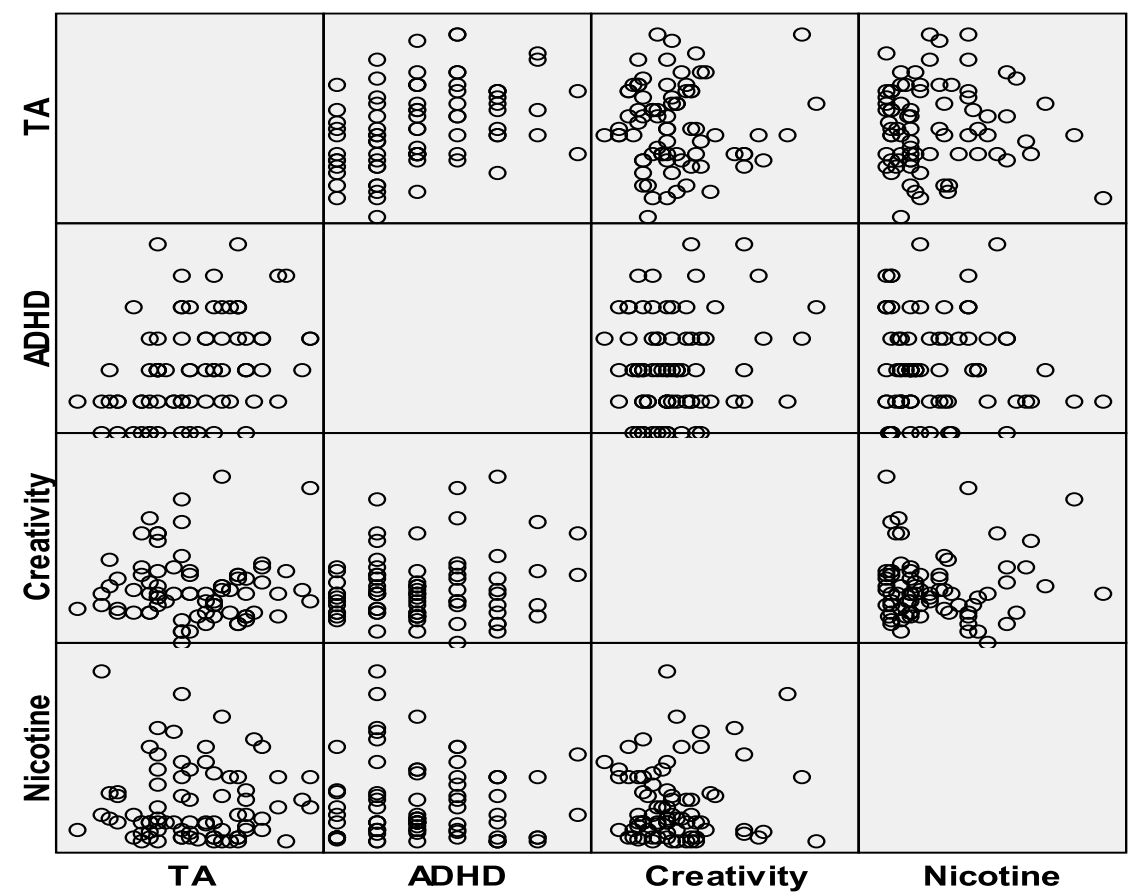

Figure 1. Matrix scatter plot to check for linearity of the variables (Trait anxiety, ADHD, Creativity and Nicotine).

Table 2 - Pearson's correlation statistics

\begin{tabular}{|l|llll|} 
& TA & ADHD & Creativity & Nicotine \\
\hline TA & 1.000 & $0.387^{*}$ & -0.001 & -0.023 \\
\hline ADHD & $0.387^{*}$ & 1.000 & 0.147 & -0.027 \\
\hline Creativity & -0.001 & 0.147 & 1.000 & 0.060 \\
\hline Nicotine & -0.023 & -0.027 & 0.060 & 1.000 \\
\hline
\end{tabular}

It was decided that Multiple Linear regression would best serve the purpose of determining the role played by each variable in predicting anxiety. Pearson's correlation was computed in order to determine the relationship between the variables. As per Table 2, a significant relationship was found between Trait Anxiety and ADHD; they were positively correlated $(r(78)=0.387, p<0.05)$.

As a result of obtaining a positive, significant correlation between Trait Anxiety and ADHD symptoms, a Linear Regression model was applied to study the variance in Trait anxiety brought about by ADHD symptoms. The default enter method was used to generate the model that could best predict TA

\begin{tabular}{|c|c|c|c|c|c|c|c|c|c|c|}
\hline \multirow[b]{2}{*}{ Model } & \multirow[b]{2}{*}{$\mathrm{R}$} & & & \multicolumn{7}{|c|}{ Change Statistics } \\
\hline & & $\begin{array}{c}\mathrm{R} \\
\text { Square }\end{array}$ & $\begin{array}{c}\text { Adjusted } \\
\text { R Sq }\end{array}$ & $\begin{array}{l}\text { Std. Error } \\
\text { of the } \\
\text { estimate }\end{array}$ & $\begin{array}{c}\text { R } \\
\text { square } \\
\text { change }\end{array}$ & $\begin{array}{c}\mathrm{F} \\
\text { change }\end{array}$ & $\begin{array}{c}\text { Df } \\
1\end{array}$ & $\begin{array}{c}\text { Df } \\
2\end{array}$ & $\begin{array}{c}\text { Sig. } \\
\text { F }\end{array}$ & $\begin{array}{l}\text { Durbin } \\
\text { Watson }\end{array}$ \\
\hline & 0.387 & 0.150 & 0.139 & 6.076 & $\begin{array}{c}0.15 \\
0\end{array}$ & 13.427 & 1 & $\begin{array}{l}7 \\
6\end{array}$ & .000 & 1.917 \\
\hline
\end{tabular}


Results obtained as seen in table 3 indicate that the $\mathrm{R}$ value was 0.387 . The $R$ square value was 0.150 which indicated that $15 \%$ of the variance in Trait Anxiety can be explained by the presence of symptoms of ADHD. The adjusted $\mathrm{R}^{2}$ value is 0.139 i.e. $13.9 \%$ of the variance in Trait Anxiety can be explained. The $\mathrm{R}$ square change tells us that if new predictors are added to the table, the change would be significant as indicated by the $\mathrm{F}$ ratio. Further the Durbin-Watson statistic is 1.917 which is very close to 2 .

\begin{tabular}{|c|c|c|c|c|c|c|}
\hline & Model & $\begin{array}{l}\text { Sum of } \\
\text { Squares }\end{array}$ & $\mathrm{df}$ & $\begin{array}{c}\text { Mean } \\
\text { Square }\end{array}$ & $F$ & Sig. \\
\hline \multirow[t]{3}{*}{1} & Regression & 495.706 & 1 & 495.706 & 13.427 & $.000^{a}$ \\
\hline & Residual & 2805.781 & 76 & 36.918 & & \\
\hline & Total & 3301.487 & 77 & & & \\
\hline & a. Predict & 5: (Consta & HD & & & \\
\hline & b. Depend & t Variable & & & & \\
\hline
\end{tabular}

The ANOVA table discusses whether the model is significantly better at predicting the outcome that using the mean as the best guess. Since the F-ratio is significant, this model is much better at predicting the presence of trait anxiety than the mean.

\section{Table 5}

Multiple Linear Regression model to predict Trait Anxiety based on Creativity, Symptoms(ADHD) and Nicotine Content.

\begin{tabular}{|c|c|c|c|c|c|c|}
\hline & & \multicolumn{2}{|c|}{$\begin{array}{l}\text { Unstandardized } \\
\text { Coefficients }\end{array}$} & \multicolumn{3}{|c|}{$\begin{array}{l}\text { Standardized } \\
\text { Coefficients }\end{array}$} \\
\hline Model & & $\mathrm{B}$ & Std. Error & Beta & $\mathrm{t}$ & Sig. \\
\hline 1 & (Constant) & 52.033 & 1.167 & & 44.591 & 0.000 \\
\hline & ADHD & 1.633 & 0.446 & 0.387 & 3.664 & 0.000 \\
\hline
\end{tabular}

The above coefficient table (Table 5) indicates that ADHD is a significant predictor of TA. The standardized Beta coefficients tell us that for one standard deviation change in the ADHD scores, TA score will increase by .387 units. The VIF values given in the collinearity statistics (1.026) also indicate that there is no possibility of multicollinearity among the predictors. The graph below indicates a normal bell shaped curve for the standardized residuals of TA. This meets the assumption of normality and the scatter plot shows the residual meeting the assumption for linearity. 
Histogram

Dependent Variable: TA

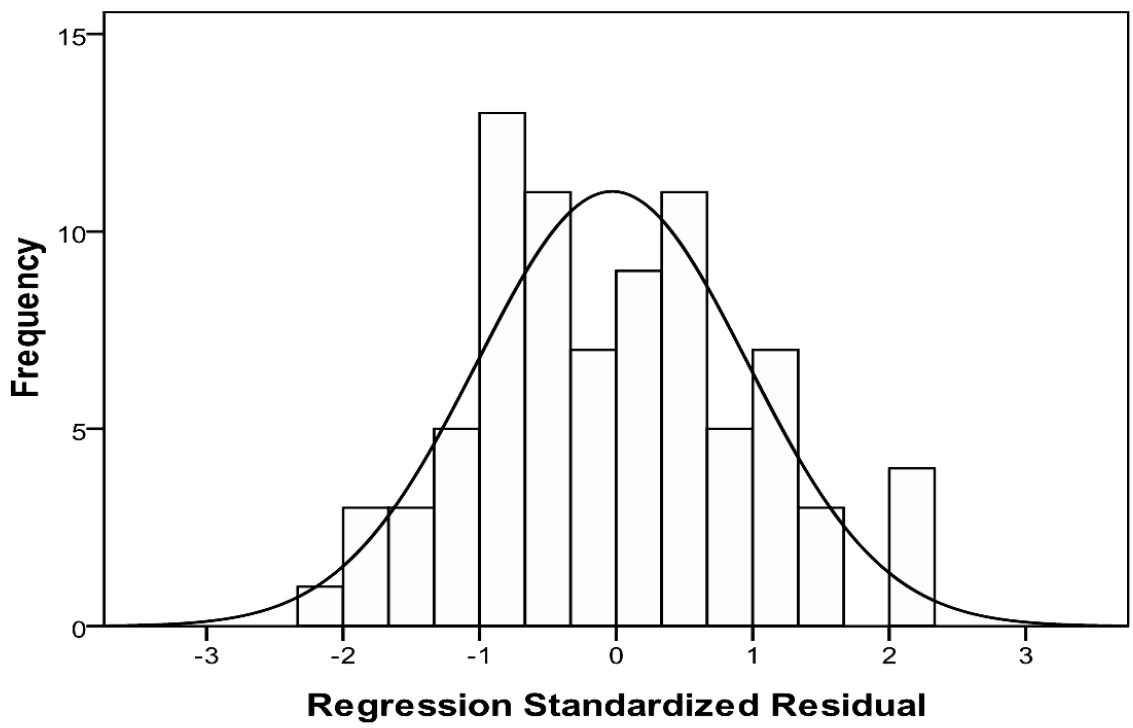

Mean $=-0.03$
Std. Dev. $=0.99$
$N=82$

Figure 2 - Bar graph and curve showing standardized residuals of Trait Anxiety.

DISCUSSION

The purpose of this research was to study the relationship between Trait Anxiety, ADHD, Nicotine and Creativity in smokers. It was found that Trait Anxiety and symptoms of ADHD had a positive correlation indicating that an increase in one would be accompanied by increase in the other. Regression analysis revealed that Trait Anxiety can be explained by the level of severity of ADHD Symptoms. In the past several researchers have studied the relation between Trait Anxiety and ADHD. Consistent with past research, it was found that individuals with symptoms of ADHD had higher Trait Anxiety (as found in the present study) and those with the inattentive type of ADHD scored higher on State Anxiety [11]. Individuals with severe symptoms of ADHD tend to experience anxiety in a more consistent manner that lasts for a longer period of time. Results of the present study also mirror the findings of a study in 2008 where it was found that trait anxiety was caused by deficiencies in the executive functioning abilities or reduced prefrontal activity [12].

Results of the present research can be explained based on a study which proposed that the relationship between nicotine and trait anxiety can be understood by considering several factors such as the self-medicating effects of nicotine and other cognitive variables such as self-efficacy levels [13]. Another study indicated that the relaxing effect of exposure to nicotine in individuals with high levels of trait anxiety may result in cravings to smoke due to the rewarding effects of nicotine. The inability to smoke in all anxiety situations may lead to a considerable amount of stress which in turn has effects on the level of trait anxiety [14]. Nicotine dependence may result in other symptoms that more accurately predict trait anxiety than the dependence itself 
The research also aimed at studying the relationship between Trait Anxiety and Creativity. The present study took into consideration the individuals Trait Anxiety and their performance on a figural task measuring creativity. As per past research in the field, state and trait anxiety differently affect ones performance on verbal and figural tasks [15]. The research suggested that anxiety and creativity present competing cognitive demands on the individual. It was found that anxiety and creativity have a significant but negative correlation. Despite of getting a negative correlation between trait anxiety and creativity, the results of the present study were nonsignificant. This could be attributed to a relatively small sample that was not completely representative of the population as a whole.

The sample size of eighty three individuals is too small to obtain significant results in the variables being measured. Data was collected by means of Google docs and not physically by the researcher. This practice, as believed by the researcher has affected the prospect of a larger sample. Minute glitches in the software and the length of the survey were some of the drawbacks of online data collection. Future researchers must target a larger sample size in order to find a significant relationship. The sample in the present study consisted mostly of college students. The age range of 19-35 years of age cannot be said to be representative of the total population. The number of working professionals and older adults in this study were comparatively fewer than the younger students. This results in an uneven distribution when the sample is seen in terms of the number of years that the individual has been smoking. Creativity being one of the predictor variables was measured using a divergent thinking scale. The measurement and scoring of creativity is extremely challenging as it involves subjectivity on the part of the scorer. Creativity can be assessed on various domains and skills. This study included only a figural test with limited items thus narrowing the scope of the other domains of creativity.

Measurement of creativity can be done based on several domains such as fluency, flexibility, originality, abstractness and elaboration. The present study only used two of these domains (fluency and originality) based on five percent of the sample data. An enhanced score on creativity can be obtained by assessing the variable using most of these domains. Another important aspect in measuring creativity is the motivation and intelligence level of the participants. This was not looked into in the present study. Lack of literature on creativity being measured in non- artistic professions has also been a drawback. By improving these issues with creativity as a measurable variable, future researchers may be able to study and understand creativity. The present study was aimed at merely studying the relation between nicotine content and variables like creativity, ADHD and anxiety based on the average nicotine consumed by the individual in one day. It does not looking into the present effects of nicotine.

The finding of this study has future implications for researchers who aim to measure variables such as creativity. By focusing on the limitations of measuring creativity faced by the researcher, future studies may benefit in terms of a more comprehensive score of creativity. Significant findings in the relation between Trait anxiety and symptoms of ADHD may provide implications to psychologists and therapists dealing with clients with ADHD and anxiety issues. The study may provide insight that will help strategize treatment plans for people with ADHD. 


\section{REFERENCES}

1. McDowell I. Anxiety. Measuring Health. ( $3^{\text {rd }}$ Ed.) New York. Oxford University Press, Inc ; 1990.

2. Spielberger CD, Sarason IS. A Cognitive Model Of Anxiety. Stress and Anxiety. (Vol 9). USA. Hemisphere Publishing Cooperation ; 1983.

3. American Psychiatric Association. Diagnostic and Statistical Manual of Mental Disorders $4^{\mathrm{TH}}$ edition text revised (DSM-IV TR). American Psychiatric Association. New Delhi. Jaypee Brothers Medical Publishers (P) Ltd ; 2000.

4. Khandwalla PN. The landscape of creativity. Fourth Eye: ExcellenceThrough Creativity (1st ed., 1). Allahabad, India: A.H. Wheeler \& Co (P) Ltd ; 1984

5. Unguetti A, Acosta A, Callejas A, Lupianez J. Attention and anxiety different attentional functioning under state and trait anxiety. Psychol Sci 2010;21(2):298-304.

6. Sylvers $\mathrm{P}$, Lilienfeld SO, La Prairie JL. Differences between trait fear and trait anxiety: Implications for psychopathology. Clin Psychol Rev 2011;31(1):122-37.

7. Bishop SJ. Trait Anxiety and Impoverished prefrontal control of attention. Nat Neurosci 2009;12(1):92-8.

8. Byron $\mathrm{K}$, Khazanchi S. A meta-analytic investigation of the relationship of state and trait anxiety to performance on figural and verbal creative tasks. Personal Soc Psychol Bull 2011;37:269-83.

9. Riedel HPR, Taylor IA, Melnyk WT. Effects of creative and non-creative problem solving on anxiety. Perceptual Motor Skills 1983;56:835-44.

10. Audrian J, Lerman C, Gomez-Caminero A, Boyd NR, Orleans CT. The role of trait anxiety in nicotine dependence. J Appl Biobehav Res 1998;3(1):29-42.

11. Scheitrum RR, Akillas E. Effects of Personality Style, Anxiety, and Depression on Reported Reasons for Smoking. J Appl Biobehav Res 2002;7(1):57-64.

12. Di Franza JR, Savageau JA, Rigotti NA, Ockene JK, McNeill AD, Coleman M, Wood C. Trait anxiety and nicotine dependence in adolescents: a report from the DANDY study. Addict Behav 2004;29(5):911-9.

13. Novak A, Burgess ES, Clark M, Zvolensky MJ, Brown RA. Anxiety sensitivity, self-reported motives for alcohol and nicotine use, and level of consumption. J Anxiety Disord $2003 ; 17(2): 165-80$.

14. Canals J, Doménech E, Bladé J. Smoking and trait anxiety. Psychol Rep 1996;79(3):80910.

15. Takemura Y, Akanuma M, Kikuchi S, Inaba Y. Cross-sectional study on the relationship between smoking or smoking cessation and trait anxiety. Prev Med 1999;29(6):496-500.

Acknowledgements - Nil

Conflict of Interest - Nil

Funding - Nil. 